\title{
Simulated Annealing and its Hybridisation on Noisy and Constrained Response Surface Optimisations
}

\author{
Pongchanun Luangpaiboon \\ Thammasat University \\ Thailand
}

\section{Introduction}

Optimisation of processes is an essential part of quality improvement in any industry. It will lead to the most efficient use of resources, with consequential environmental and financial benefits. Most manufacturing processes have some variables. Conventionally, a single response of our interest is influenced by these process variables. Care must be taken to operate industrial processes within safe limits, but optimal conditions are rarely attained and increased international competition means that deviations from the optimum can have serious financial consequences. In many cases the optimum changes with time and there is a need for a routine mode of operations to ensure that the process always operates at optimal or near-optimal conditions.

Response Surface Methodology (RSM) is a bundle of mathematical and statistical techniques that are helpful for modelling and analysing those problems. RSM describes how the yield of a process varies with changes in influential variables (Box and Draper, 1987). An objective of RSM is to determine the operating conditions or proper levels of these process variables to optimise the response. Estimation of such surfaces, and hence identification of near optimal settings for influential process variables is an important practical issue with interesting theoretical aspects. Many systematic methods for making an efficient empirical investigation of such surfaces have been proposed in the last fifty years. These are sometimes referred to as evolutionary operation (EVOP).

On the theory and practice of RSM, it is assumed that the mean response ( $\eta$ ) is related to values of the process variables $\left(x_{1}, x_{2}, \ldots, x_{k}\right)$ by an unknown function $f$. The functional relationship between the mean response and k process variables can be written as $\eta=f(X)$, if $X$ denotes a column vector with elements $x_{1}, x_{2}, \ldots, x_{k}$. We usually represent a three dimensional response surface graphically as shown in Fig. 1, where $\eta$ is plotted versus the levels of $x_{1}$ and $x_{2}$. To help visualise the shape of a response surface, we often plot the contours of the response surface. In the contour plot, lines of constant response are drawn in the $\mathrm{x}_{1}-\mathrm{x}_{2}$ plane. Each contour corresponds to a particular height of the response surface. 


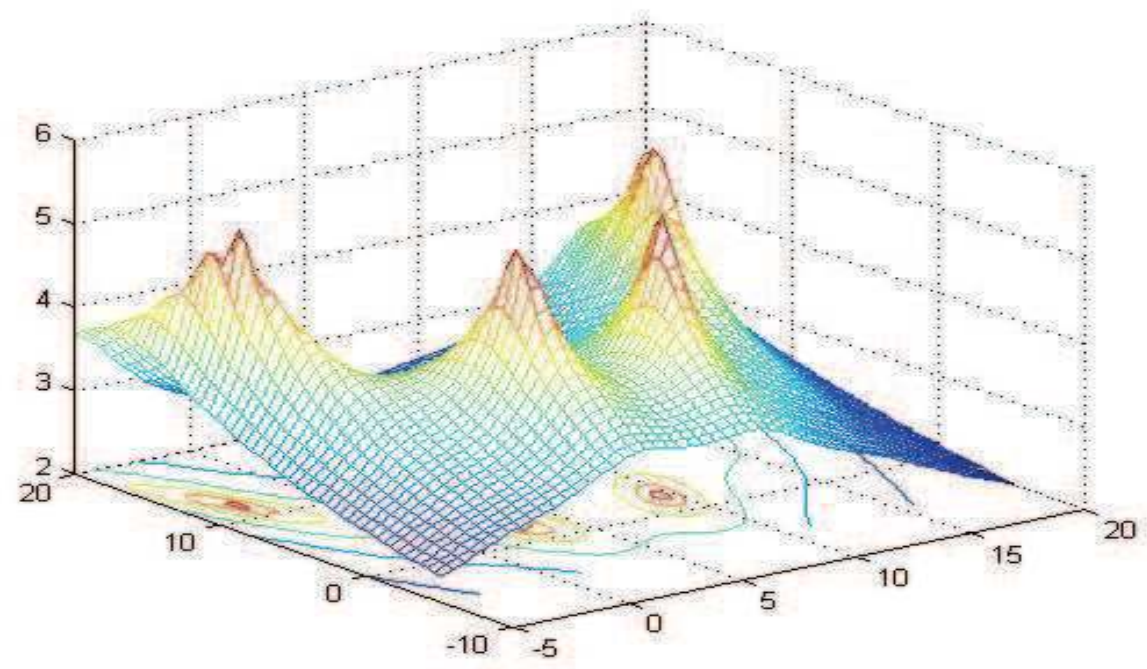

Fig. 1. A three dimensional response surface showing the expected yield with its contour plot

RSM uses statistical models, and therefore practitioners need to be aware that even the best statistical model is an approximation to reality. In practice, both the models and the parameter values are unknown, and subject to uncertainty on top of ignorance. Of course, an estimated optimal design point might not be the optimum in reality, because of the errors of the estimates and of the inadequacies of the model. Nonetheless, RSM has an effective track-record of helping researchers improve products and processes.

The optimisation of response surfaces is different from the conventional optimisation in various ways. Response surface optimisation is mainly an iterative procedure (Blum and Roli, 2003). Experiments, performed in one set, result in fitted models that indicate where to find improved levels of process variables in the next experiment. Thus, the coefficients in the fitted model may change during the response surface optimisation process. Moreover, the response surfaces are fitted from current experimental design points that usually contain random variability due to unknown or uncontrollable causes. If an experiment is repeated, the result will bring a different fitted response surface that may lead to different optimal levels of process variables. Therefore, sampling variability or noisy measurements should be concerned in this optimisation. It differs from the conventional optimisation in which the functions to be optimised are fixed and given.

Nowadays, many entrepreneurs face to extreme conditions for instances; costs, quality, sales and services. Technology has always been intertwined with our demands. Then almost manufacturers or assembling lines adopt it and come out with more complicated process inevitably. At this stage, product and process improvement need to be shifted from competitors with sustainability. Moreover, there are currently some problems associated with various process responses. If one can be assigned as the primary or the most important response and others return to be merely secondary responses or problem constraints. The 
constrained response surface optimisation is then proposed to find the new setting of optimal levels of process variables leading to the optimal level of the primary response and satisfying all other constraints of secondary responses. Moreover, lower and upper bounds of process variables can be included in order to avoid achieved solutions that extrapolate too far outside the feasible region of the experimental design points.

These difficulties associated with using response surface optimisations on complex, largescale, noisy and constrained engineering problems have contributed researchers to seek the alternatives, based on simulations, learning, adaptation and evolution to solve these problems. Natural intelligence-inspired approximation optimisation techniques called metaheuristics are then introduced. The common factor in meta-heuristics is that they combine rules and randomness to imitate natural phenomena. They widely grow and apply to solve many types of problems. The major reason is that meta-heuristic approaches can guide the stochastic search process to iteratively seek near optimal solutions in practical and desirable computational time. The meta-heuristic algorithms are then received more attention in the last few decades. They can be categorised into three classes: biologically-based inspiration, e.g. Genetic Algorithm or GA (Goldberg, 1989), Neural Network or NN (Haykin, 1999), Ant Colony Optimisation or ACO (Merz and Freisleben, 1999), Artificial Immune System (AIS) by Dasgupta (1998) and Hart and Timmis (2008), Particle Swarm Optimisation or PSO (Kennedy and Eberhart, 2001) and Shuffled Frog Leaping Algorithm or SFLA (Eusuff et al., 2006); socially-based inspiration, e.g. Taboo Search or TS (Glover, 1986); and physicallybased inspiration such as Simulated Annealing or SA.

In this research we examine steepest ascent, simulated annealing and ant colony optimisation algorithms on various hypothetical unconstrained response surfaces with 2-5 process variables. Considering the solution space in a specified region, some surfaces contain global optimum and multiple local optimums and some are with the curved ridge. The comparisons are made for four different levels of measurement noise on the response. The noise is taken to be independently and normally distributed with mean of zero and standard deviations of $0,1,2$ and 3. There are 100 realisations in each experimental level of measurement noise to check a consistency of numerical results. These algorithms have been developed through computer simulation programs. The effects of different choices of algorithms on different performance measures are investigated. The performance achievements consist of Taguchi's signal to noise ratio of the larger the better case, mean and standard deviation of responses. All the algorithms are run until they converge. The additional comparisons are made to constrained processes on turning machining and spring force problems (Khan et al., 1997). In order to improve the fine-tuning characteristic of the single algorithm, a hybridisation based on the most efficient algorithms are also introduced. This paper is organised as follows. Sections 2, 3 and 4 describe the details of conventional steepest ascent, simulated annealing and ant colony optimisation algorithms, respectively. Section 5 provides experimental results on noisy unconstrained and constrained response surface optimisation problems. The conclusions and recommendations are also summarised in Section 6. It is followed by acknowledgments and references.

\section{Steepest Ascent Algorithm (ST)}

Box and Draper (1987) described a mechanistic model as a physically based mathematical formula, which represents the yield of a process in terms of those process variables, which 
are known to influence it. In contrast to this, a relatively simple function or typically some fitted polynomial which approximates the physical formula at least locally, is referred to as an empirical model. Often, the mechanistic model is a large-scale description of a process, which can be used to define some safe and economically viable region of operation. Empirical models can then be used to identify optimal conditions within this region.

Suppose the yield of a system depends on a number $(\mathrm{k})$ of process variables, which are restricted to some region of safe operation. In geometric terms this equation can be represented by a surface in the $k+1$ dimension. The expected value of the yield is some unknown function of the $\mathrm{k}$ process variables, and the measured yields will vary about their expected values because of random errors. These errors are comprised of natural variation in the process and measurement errors, which occur when monitoring the yield, and are assumed to have a mean of zero and to be uncorrelated with the values taken by the $\mathrm{k}$ process variables. Errors in measuring the values of the $\mathrm{k}$ process variables are usually assumed to be negligible in comparison with the random errors associated with the yield. These random errors are also often assumed to be independently drawn from a normal distribution with constant variance, although this is not a requirement for the validity of the techniques presented here.

There are many response surface optimisation methods. One among those is called the steepest ascent algorithm (ST). It aims to seek a region around the global optimum via a first-order polynomial model from a factorial experimental design or its fraction. The ST procedure is that a hyperplane is fitted to the results from the initial design points. The direction of steepest ascent on the hyperplane is then determined by using a principle of regression analysis. The next run is carried out at a design point, which is some fixed distance in this direction, and further runs are carried out by continuing in this direction until no further increase in yield is noted. When the response first decreases another factorial design is carried out, centred on the preceding design point. A new direction of steepest ascent is estimated from this latest experiment. Provided at least one of the coefficients of the hyperplane is statistically significantly different from zero, the search continues in this manner (Myers and Montgomery, 1995). The pseudo code is used to briefly explain to all the procedures of the ST shown in Fig. 2.

\section{Procedure of the ST Metaheuristic()}

While (termination criterion not satisfied) - (line 1)

Initialise ST parameters: the unit of the step length, limited moves and the significance level for tests of significance of slopes;

Randomly select a starting point to be the centre of a factorial design;

Calculate a fitness value in each design point at the centre and peripheral locations;

\section{Schedule activities}

Determine the significant first order model from the factorial design points;

\section{Schedule activities}

Move along the steepest ascent's path with a step length ( $\Delta)$;

Compute the fitness value;

if the new one is greater than the preceding then

Move ahead with another $\Delta$;

else

Calculate two more fitness values to verify the descending trend; 
if one of which fitness values turn out to be greater than a preceding coordinate's fitness value then

Use the biggest fitness value to continually move along the same path; else

Use the closest preceding point as the centre for a new factorial design; end if

end if

end schedule activities

end schedule activities

end while

end procedure

Fig. 2. Pseudo Code of the ST Metaheuristic.

\section{Simulated Annealing Algorithm (SA)}

Kirkpatrick and his colleagues (Kirkpatrick et al., 1983) first proposed a detailed analogy of an annealing in solids to the combinatorial optimisation called as Simulated Annealing (SA). The annealing processes are performed by first melting the system at a high temperature, then lowering the temperature slowly, finally spending a long time at freezing temperatures. During the annealing process, the time spent at each temperature level must be sufficiently long to allow the system to reach a thermal equilibrium or a steady state. If care is not taken in adhering to the annealing temperature schedule, undesirable random fluctuations may cause the shift of the ground state. The basic idea of statistical mechanics initiates a generalisation of the iterative improvement or the search for a better solution of the combinatorial optimisation.

The SA has been derived from an interesting analogy between problems in statistical mechanics and multivariate or combinatorial optimisation. This algorithm is a set of rules for searching large solution spaces in a manner that mimics the annealing process of metals. The algorithm simulates the behaviour of an ensemble of atoms in equilibrium at a given finite temperature (Bohachevsky et al., 1986) and its original framework can be traced to Metropolis et al. This algorithm has been regularly used in global function optimisation and statistical applications.

In case of maximisation, procedures of this algorithm start at a corresponding initial value of the objective function. The new objective value will be then determined. The new solution will be unconditionally accepted if its objective value is improved and the process regularly continues. Otherwise the difference or size of increment in objective values, $\delta y$, is calculated and with an auxiliary experiment the new solution would be accepted with probability $\mathrm{P}(\delta \mathrm{y})$. This stochastic element is from Monte Carlo sampling. It occasionally allows the algorithm to accept the new solution to the problems, which deteriorate rather than improve the objective function value. The pseudo code is used to briefly explain to all the procedures of the SA shown in Fig. 3.

\section{Procedure of the SA Metaheuristic()}

Initialise SA parameters: number of iterations, a reducing rate, starting and freezing temperatures;

Find a starting temperature;

Find a random starting solution (s); 


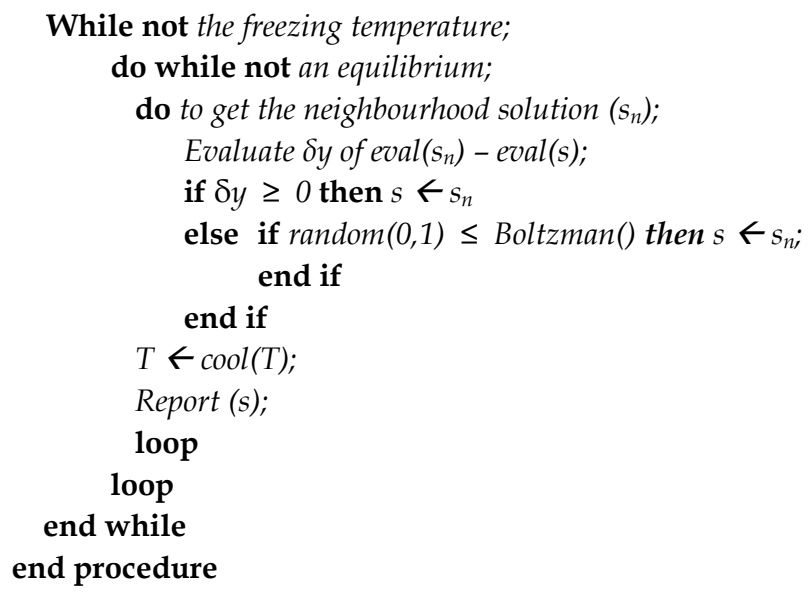

Fig. 3. Pseudo Code of the SA Metaheuristic.

\section{Ant Colony Optimisation Algorithm (ACO)}

Ant Colony Optimisation (ACO) was first proposed by Dorigo and his colleagues (Dorigo et al., 1996) as a multi-agent approach to optimisation problems, such as a travelling salesman problem (TSP) and a quadratic assignment problem (QAP). There is currently a lot of ongoing activity in the scientific community to extend or apply ant-based algorithms, especially in various discrete optimisation problems (Dorigo and Stutzle, 2004). Recent applications cover problems like a vehicle routing, a plant layout and so on. The ACO is inspired by observations of real ant colonies. Behaviour is direct more to the survival of the colony as a whole than to that of a single individual component of the colony. Social insects have captured the attention from many scientists because of a structure of their colonies, especially when compared with a relative simplicity of the colony's individual (Dorigo and Blum, 2005).

An important and interesting issue of ant colonies is their foraging behaviour and in particular how ants can find shortest paths between food sources and their nest. While walking from food sources to the nest and vice versa, ants deposit on the ground a substance called pheromone, forming in this way a pheromone trail. Ants can smell pheromone. When choosing their way, they tend to choose paths marked by strong pheromone concentrations. The pheromone trail allows the ant to find their way back to the food source or to the nest. Also, it can be used by other ants to find the location of the food sources found by their nest mates. The pseudo code is used to briefly explain to all the procedures of the ACO shown in Fig. 4.

\section{Procedure of the ACO Metaheuristic()}

While (termination criterion not satisfied) - (line 1)

Initialise ACO parameter: number of iterations, ants and moves;

Schedule activities

Make the path or step for each ant;

Evaluate the fitness values; 
Compare fitness values;

if no improvement of the fitness value then

Communicate with the best ant fitness value;

else

Make the path or step from the local trap to best ant;

if ant found the better response function then

Go to line 5;

else end if

Wait for the best ant communication;

end if

end schedule activities

end while

end procedure

Fig. 4. Pseudo Code of the ACO Metaheuristic.

\section{Experimental Results}

Response surface algorithms of the ST, SA and ACO with some modifications are applied to engineering optimisation problems with continuous process variables. Several examples taken from the standard benchmark engineering optimisation literature are used to show how the proposed approaches work. These examples have been previously solved using a variety of other techniques, which are useful to demonstrate the validity, effectiveness and robustness of the proposed algorithms. The performance measures of these algorithms consist of the sample mean and standard deviation (S) of yields including Taguchi signal to noise ratio in the cases of 'the larger the better', SN1, and 'the smaller the better', SN2 (Taguchi and $\mathrm{Wu}, 1980)$ :

$$
\begin{aligned}
& \mathrm{SN} 1=-10^{*} \log \left(\sum\left(1 / \mathrm{yi}^{2}\right) / \mathrm{n}\right) \\
& \left.\mathrm{SN} 2=-10^{*} \log \left(\sum\left(\mathrm{yi}^{2}\right) / \mathrm{n}\right)\right)
\end{aligned}
$$

in which $y_{i}$ represents the best yield at the end of trial $i$, and $n$ is the number of trials. Some experiments include the design points used to achieve the final solution and the computational times as the additional performance measures.

\subsection{Noisy and unconstrained response surface optimisation}

In this subsection, eight non-linear continuous unconstrained functions (Fig. 5-12) in the context of response surface were used to test performance measures of the related algorithms whilst searching for the optimum. It is assumed that the current operating conditions correspond to process variables are randomly taken as the starting point for the algorithms. The comparisons are made for four different levels of measurement noise on the response. There are 100 realisations in each experimental level of measurement noise. The noise is taken to be independently and normally distributed with mean of zero and standard deviations of $0,1,2$ and 3 .

A. Branin Function

$$
f(x)=5-\log _{10}\left[\left(x_{2}-\frac{5.1}{4 \pi^{2}} x_{1}^{2}+\frac{5}{\pi} x_{1}-6\right)^{2}+\left(10-\frac{5}{4 \pi} \cos \left(x_{1}\right)\right)+10\right]
$$




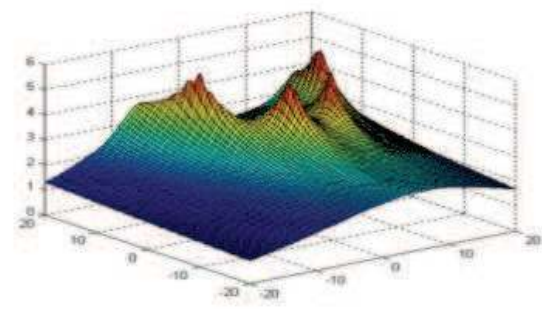

(a)

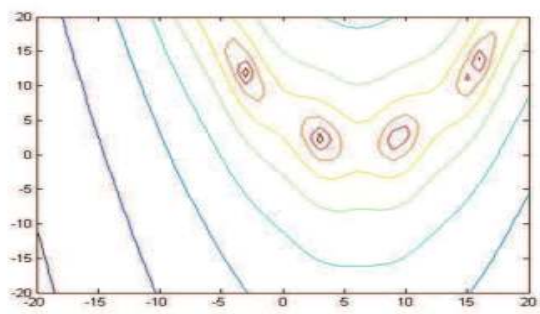

(b)

Fig. 5. Branin surface (a) and its contour (b).

B. Camelback Function

$f(x)=10-\log _{10}\left[x_{1}^{2}\left(4-2 \cdot 1 x_{1}^{2}+\frac{1}{3} x_{1}^{4}\right)+x_{1} x_{2}+4 x_{2}^{2}\left(x_{2}^{2}+1\right)\right]$

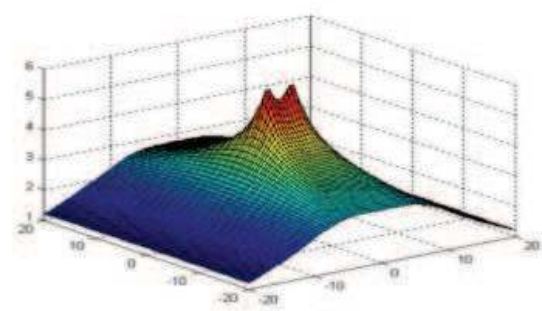

(a)

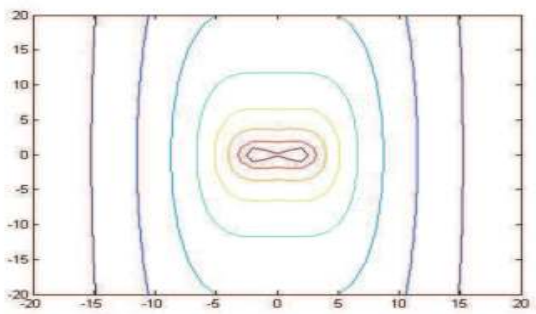

(b)

Fig. 6. Camelback surface (a) and its contour (b).

\section{Goldstein-Price Function}

$f(x)=10+\log _{10}\left[1 /\left\{1+\left(1+x_{1}+x_{2}\right)^{2}\left(19-14 x_{1}+3 x_{1}^{2}-14 x_{2}+6 x_{1} x_{2}+3 x_{2}^{2}\right)\right\}\right.$ *

$\left.\left\{30+\left(2 x_{1}-3 x_{2}\right)^{2}\left(18-32 x_{1}+12 x_{1}^{2}+48 x_{2}-36 x_{1} x_{2}+27 x_{2}^{2}\right)\right\}\right]$

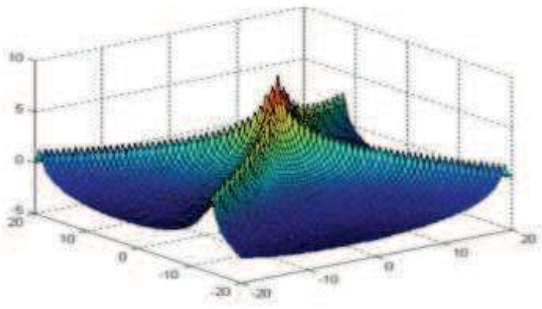

(a)

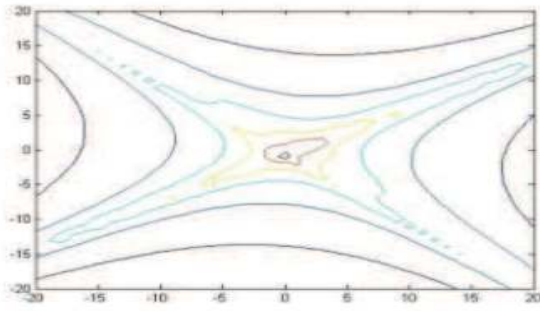

(b)

Fig. 7. Goldstein-Price surface (a) and its contour (b).

\section{Parabolic Function}

$f(x)=12-\left(\sum_{j=1}^{k} x_{j}^{2} / 100\right)$ 


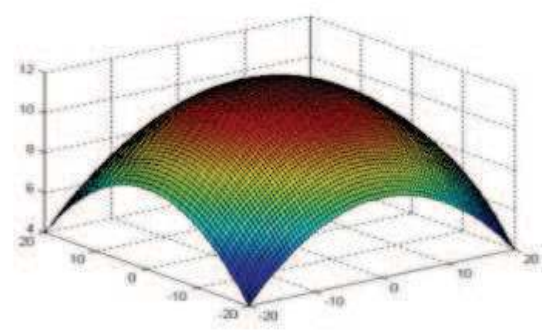

(a)

Fig. 8. Parabolic surface (a) and its contour (b).

E. Rastrigin Function

$$
f(x)=80-\left[20+\sum_{j=1}^{k} x_{j}^{2}-10\left(\sum_{j=1}^{k} \cos 2 \pi x_{j}\right)\right]
$$

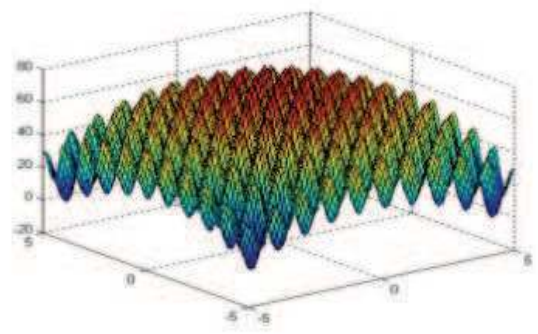

(a)

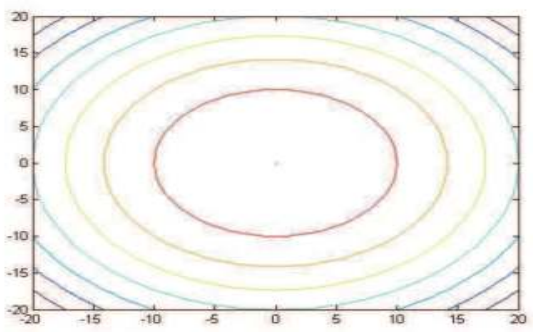

(b)

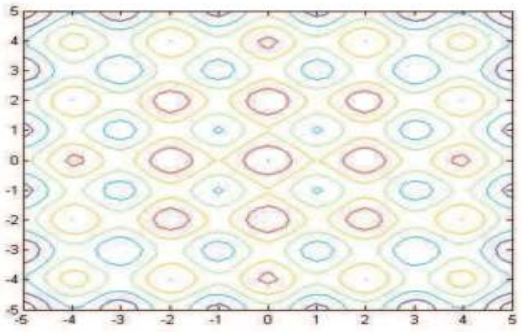

(b)

Fig. 9. Rastrigin surface (a) and its contour (b).

F. Rosenbrock Function

$$
f(x)=70\left[\left(\left\{20-\left(\left(-x_{1} / a_{1}\right)^{2}+\sum_{j=2}^{k}\left[\left(x_{j} / a_{j}\right)-\left(x_{1} / a_{1}\right)^{2}\right]^{2}\right)\right\}+150\right) / 170\right]+10 ;
$$

where $\mathrm{a}_{1}, \mathrm{a}_{2}, \mathrm{a}_{3}, \mathrm{a}_{4}$, and $\mathrm{a}_{5}$ are set at $6,-7,-2,4$ and 5 , respectively.

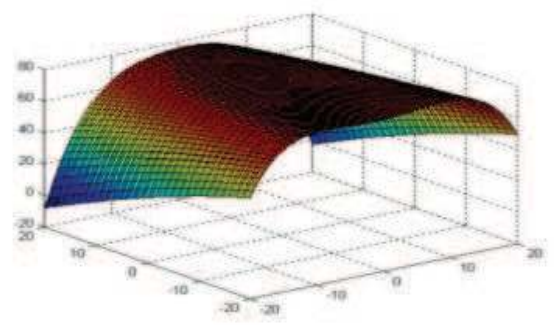

(a)

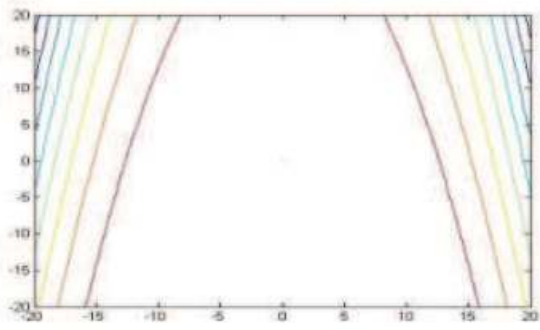

(b)

Fig. 10. Rosenbrock surface (a) and its contour (b). 
G. Shekel Function

$$
f(x)=100 \sum_{i=1}^{5} \frac{1}{c_{i}+\sum_{j=1}^{k}\left(x_{j}-a_{i j}\right)^{2}} ;
$$

where the parameters of local optimum locations $\left(\mathrm{a}_{\mathrm{ij}}\right)$ and the local peak magnitude values $\left(c_{i}\right)$ are shown on the table below.

\begin{tabular}{|c|c|c|c|c|c|c|}
\hline \multirow{2}{*}{$\mathrm{i}$} & \multicolumn{7}{|c|}{$\mathrm{a}_{\mathrm{ij}}$} \\
\cline { 2 - 7 } & \multicolumn{7}{|c|}{$\mathrm{j}$} \\
\cline { 2 - 7 } & 1 & 2 & 3 & 4 & 5 & $\mathrm{c}_{\mathrm{i}}$ \\
\hline 1 & 4 & 6 & -2 & 2 & 4 & 9 \\
\hline 2 & 0 & 0 & -8 & -5 & 6 & 20 \\
\hline 3 & -8 & 3 & 4 & 1 & 5 & 14 \\
\hline 4 & -8 & -8 & 1 & -7 & -1 & 11 \\
\hline 5 & 6 & -7 & -2 & 4 & 2 & 6 \\
\hline
\end{tabular}

Table 1. Shekel function parameters

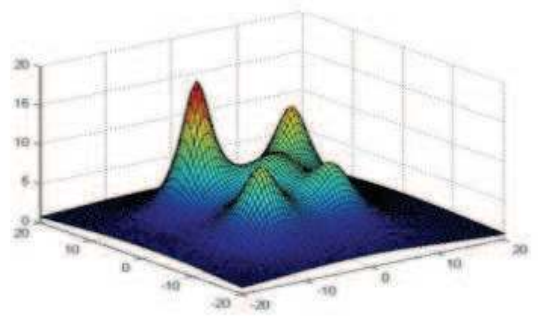

(a)

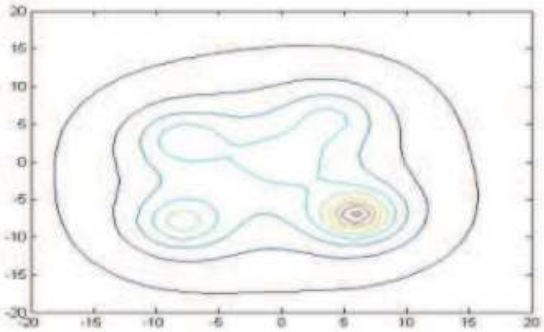

(b)

Fig. 11. Shekel surface (a) and its contour (b).

H. Styblinski Function

$$
f(x)=275-\left[\left(\frac{\left(x_{1}^{4}-16 x_{1}^{2}+5 x_{1}\right)}{2}\right)+\left(\frac{\left(x_{2}^{4}-16 x_{2}^{2}+5 x_{2}\right)}{2}\right)+\sum_{j=3}^{5}\left(x_{j}-1\right)^{2}\right]
$$

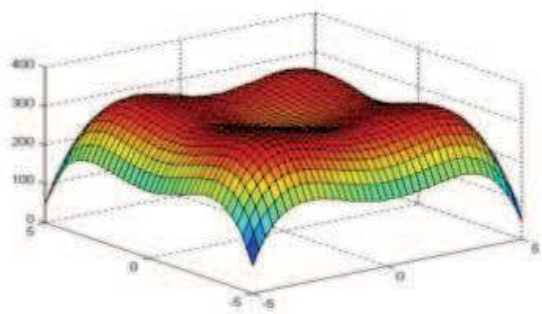

(a)

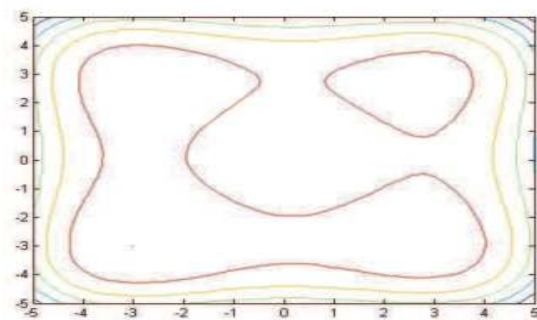

(b)

Fig. 12. Styblinski surface (a) and its contour (b). 
In this work, a computer simulation program was developed using Matlab 2006v.7.3B, and EVOPtimiser v.1.1.0. A Laptop computer with ASUS F83SE 2.20GHz Core Two T6600 processor and 4 GB RAM was used for all computational experiments. It is stated that some heuristic parameters have to be only positive integers. Consequently the process will confront with round-up error that would probably create a premature stop. The first phase of the designed experiments was aimed to investigate the appropriate parameter settings of the ST, SA and ACO algorithms. The ST contains three parameters namely, the number of iterations ( $\left.\alpha_{\mathrm{ST}}\right)$, limited moves $\left(\beta_{\mathrm{ST}}\right)$ and the unit of the step length $\left(\gamma_{\mathrm{ST}}\right)$. The SA parameters are the number of iterations $\left(\alpha_{\mathrm{SA}}\right)$, the starting temperature $\left(\beta_{\mathrm{SA}}\right)$ and the reducing rate $\left(\gamma_{\mathrm{SA}}\right)$. Finally the ACO contains three parameters of the number of iterations $\left(\alpha_{A C O}\right)$, ants $\left(\beta_{A C O}\right)$ and moves (YACO).

All parameters were considered at three levels and these values were based on the suggestions related to the algorithms available in the literatures. The experimental results were analysed via the Taguchi analyses as shown in Table 2 for the Branin function without noise and all main effects are given in Fig. 13. The results provided the most influential parameter of the number of limited moves via the largest magnitude (Delta) of the difference from all three levels or the first rank. The most proper level for the three parameters were 4000, 200 and 0.05 for the number of iterations, limited moves and step lengths, respectively. The overall parameter levels are summarised in Table 3.

\begin{tabular}{|c|c|c|c|}
\hline Level & $\alpha_{\mathrm{ST}}$ & $\beta_{\mathrm{ST}}$ & $\gamma \mathrm{ST}$ \\
\hline 1 & 5.911 & 5.916 & 5.915 \\
\hline 2 & 5.912 & 5.912 & 5.912 \\
\hline 3 & 5.910 & 5.906 & 5.906 \\
\hline Delta & 0.002 & 0.010 & 0.008 \\
\hline Rank & 3 & 1 & 2 \\
\hline
\end{tabular}

Table 2. Taguchi analyses of the ST parameters on the Branin function without noise

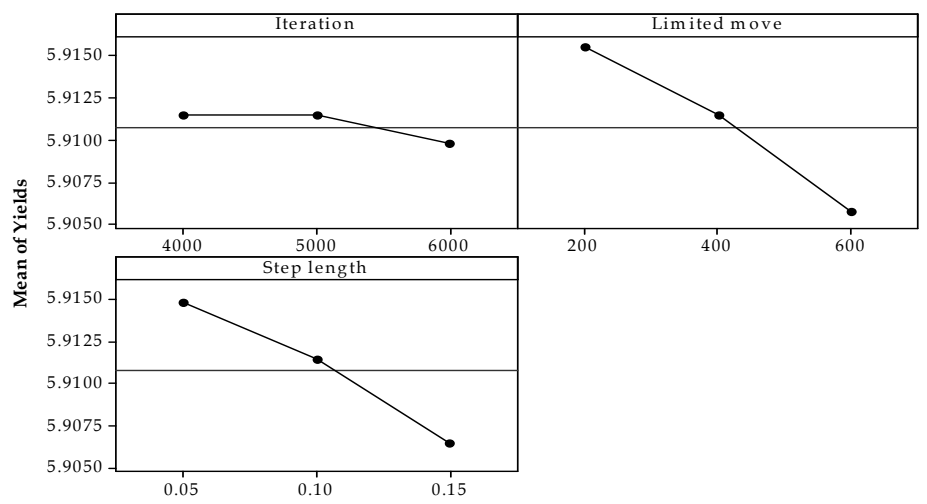

Fig. 13. Main effect plot of the ST parameters on the Branin function without noise

From the Taguchi analysis table, the algorithm parameters were set at the same levels throughout to promote an ease of use in all classes of equations. Under a consideration of recommended levels of the algorithm parameters, those may bring the benefit to solve 
industrial processes when the nature of the problems can be categorised as unimodal, multimodal or curve ridge including the mixed nature of multimodal and curve ridge response surfaces.

\begin{tabular}{|c|c|c|c|c|c|c|c|c|c|}
\hline \multirow{2}{*}{ Surface } & \multicolumn{3}{|c|}{ ST } & \multicolumn{3}{c|}{ SA } & \multicolumn{3}{c|}{ ACO } \\
\cline { 2 - 11 } & $\mathrm{a}_{\mathrm{ST}}$ & $\beta_{\mathrm{ST}}$ & YSA & $\mathrm{a}_{\mathrm{SA}}$ & $\beta_{\mathrm{SA}}$ & $\gamma_{\mathrm{SA}}$ & $\mathrm{a}_{\mathrm{ACO}}$ & $\beta_{\mathrm{ACO}}$ & $\gamma_{\mathrm{ACO}}$ \\
\hline Branin & 4000 & 200 & 0.05 & 150 & 3 & 0.9 & 5 & 40 & 10 \\
\hline Parabolic & - & - & - & 150 & 1 & 0.9 & - & - & - \\
\hline Rosenbrock & 5000 & 400 & 0.10 & 120 & 2 & 0.9 & - & - & - \\
\hline Shekel & 4000 & 200 & 0.05 & 150 & 1 & 0.9 & 5 & 40 & 10 \\
\hline
\end{tabular}

Table 3. Taguchi analyses of the algorithm parameters on four functions without noise

For the ST algorithm, preferable levels of the number of iterations, limited moves and the unit of the step length are set at 4000, 200 and 0.05, respectively. While the SA parameters of the number of iterations, the starting temperature and the reducing rate are set at 120,1 and 0.9 , respectively. It is suggested that the setting of the ACO parameters on the number of iterations, ants and moves should be set at 5, 40 and 10, respectively.

The next phase of experiments was aimed to comparatively study the performance of the algorithms improving the process towards the optimum. The appropriate settings of all algorithm parameters determined in the previous experiment were applied. The proposed algorithms are designed to use three performance measures as improving trigger, rather than ordinary yields. The computational results obtained from 100 realisations were then analysed in terms of the sample mean and standard deviation including Taguchi signal to noise ratio.

The first scenario was to determine the effects of an increase in process variables on the performance measures of all three algorithms. It can be seen that the performances of the ACO based on the Parabolic surface were obviously insensitive to the increase of process variables according to the mean, the standard deviation and the signal to noise ratio. However, the SA provided the more preferable when compared with the standard deviation. The sensitivity results to an increase of process variables on the Parabolic surface were shown in Fig. 14. In general, the ACO seemed to be the insensitive strategy that only worked well on all surfaces in terms of the sample means and signal to noise ratios for all levels of process variables. The SA was rather sensitive to the number of process variables, but this may not be a serious drawback in the context of automatic process control.

The second scenario was to determine the effects of an increase in the noise standard deviation on the performance measures of all three algorithms. On all surfaces, the algorithms provided the same level of performance measures of the sample mean, standard deviation and signal to noise ratio when the standard deviation of the errors was low. However, when the standard deviation of the errors increased, the ACO can be the only strategy to rely upon to locate the optimum on all performance measures, especially the signal to noise ratio on the Camelback multi peak surface (Fig. 15). 

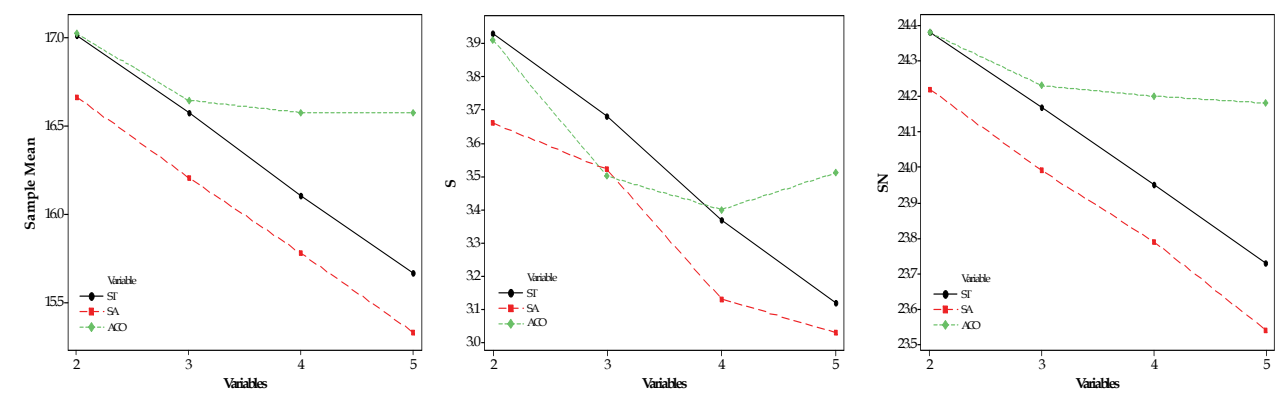

Fig. 14. Sensitivity analysis on all algorithms to an increase of process variables for the Parabolic function.
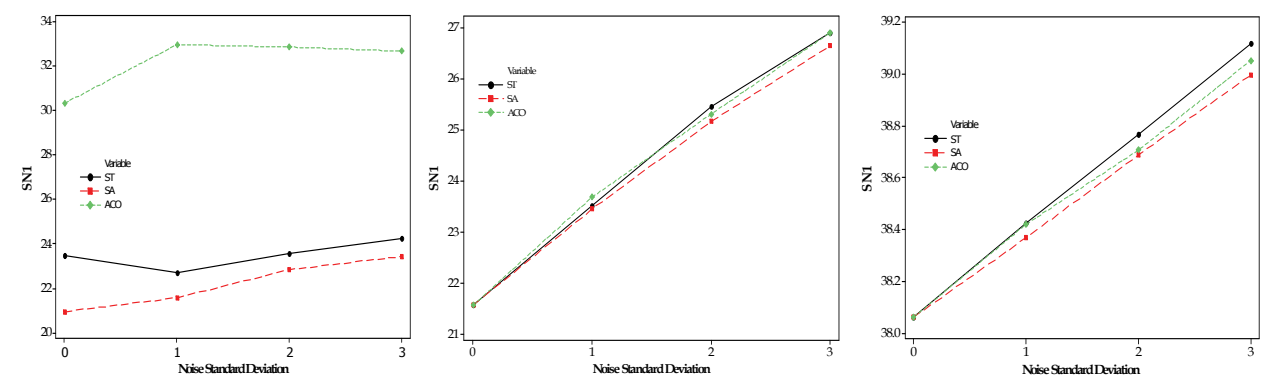

Fig. 15. Sensitivity analyses on the SN1 to an increase of the noise standard deviation for the Camelback, Parabolic and Rosenbrock functions.

From Table 4, it can be seen that the ACO found the better solutions in terms of the sample mean of the yields on all response surfaces with two process variables. The number of design points and computational time for all tested functions for the SA were dramatically better than those results obtained from the ACO. On average the computational time taken by the SA was on average 25 times quicker than the computational time required by the ACO. The average of the process yields on the Parabolic and Rosenbrock functions were not statistically significant at $95 \%$ confidence interval or there was no difference among these algorithms.

The additional experimental results on surfaces with three, four and five similarly suggested that only the ACO can provide an acceptable solution or even an optimal solution. The average computational time required by the ST and the SA was dramatically faster than the ACO. However, the SA significantly gave the fewer design points when compared as shown in Table 5. In summary, when the surface is more complicated especially with three, four and five process variables or higher levels of noise, the ACO seems more suitable to exploit a solution space as a local search without a consideration of the computational time and design points. Although the SA is quick to converge to the optimum on the design points, some of these runs lead to relatively low yields.

From experimental results above we can conclude the performance measures of the best so far response, Insensitivity to Noise, design points and computational time each algorithm in 
Table 6. Most of the best so far responses from the ACO are quite close to the optimum and insensitive to various conditions, but the SA can quickly converge to the optimum when compared. A hybridisation of the ACO and the SA are then selected to determine the performances of various industrial problems.

\begin{tabular}{|l|l|c|c|c|c|}
\hline \multicolumn{1}{|c|}{ Model } & \multicolumn{1}{|c|}{ Response } & P-Value & ST & SA & ACO \\
\hline Branin & Yield & 0.007 & & & $\checkmark$ \\
\hline & Design Point & 0.000 & & $\checkmark$ & \\
\hline & Computational Time & 0.000 & $\checkmark$ & $\checkmark$ & \\
\hline Camelback & Yield & 0.000 & & & $\checkmark$ \\
\hline & Design Point & 0.000 & & $\checkmark$ & \\
\hline Goldstein Price & Computational Time & 0.000 & $\checkmark$ & $\checkmark$ & \\
\hline & Yield & 0.000 & & & $\checkmark$ \\
\hline & Design Point & 0.000 & & $\checkmark$ & \\
\hline Parabolic & Computational Time & 0.000 & $\checkmark$ & $\checkmark$ & \\
\hline & Yield & 0.843 & & & \\
\hline & Design Point & 0.000 & & $\checkmark$ & \\
\hline Rastrigin & Computational Time & 0.000 & $\checkmark$ & $\checkmark$ & \\
\hline & Yield & 0.000 & & & $\checkmark$ \\
\hline & Design Point & 0.000 & & $\checkmark$ & \\
\hline Rosenbrock & Computational Time & 0.000 & $\checkmark$ & $\checkmark$ & \\
\hline & Yield & 0.625 & & & \\
\hline & Design Point & 0.000 & & $\checkmark$ & \\
\hline Shekel & Computational Time & 0.000 & & $\checkmark$ & \\
\hline & Yield & 0.000 & & & $\checkmark$ \\
\hline & Design Point & 0.000 & & $\checkmark$ & \\
\hline Styblinski & Computational Time & 0.000 & $\checkmark$ & $\checkmark$ & \\
\hline & Yield & 0.000 & $\checkmark$ & & $\checkmark$ \\
\hline & Design Point & 0.000 & & $\checkmark$ & \\
\hline & Computational Time & 0.000 & & $\checkmark$ & \\
\hline
\end{tabular}

Table 4. Performance measures on all tested problems with two process variables

\begin{tabular}{|c|l|c|c|c|c|c|c|}
\hline \multirow{3}{*}{ Model } & \multirow{2}{*}{ Response } & \multicolumn{3}{|c|}{ Variable } & \multirow{3}{*}{ ST } & \multirow{3}{*}{ SA } & \multirow{2}{*}{ ACO } \\
\cline { 3 - 5 } & & 3 & 4 & 5 & \\
\cline { 3 - 5 } & & $\begin{array}{c}\text { P- } \\
\text { Value }\end{array}$ & $\begin{array}{c}\text { P- } \\
\text { Value }\end{array}$ & $\begin{array}{c}\text { P- } \\
\text { Value }\end{array}$ & & & \\
\hline Parabolic & Yield & 0.774 & 0.413 & 0.095 & & & \\
\hline & Design Point & 0.000 & 0.000 & 0.000 & & $\checkmark$ & \\
\hline & Computational Time & 0.000 & 0.000 & 0.000 & & $\checkmark$ & \\
\hline Rastrigin & Yield & 0.000 & 0.000 & 0.000 & & & $\checkmark$ \\
\hline & Design Point & 0.000 & 0.000 & 0.000 & & $\checkmark$ & \\
\hline & Computational Time & 0.000 & 0.000 & 0.000 & & $\checkmark$ & \\
\hline Rosenbrock & Yield & 0.153 & 0.009 & 0.000 & & & $\checkmark$ \\
\hline & Design Point & 0.000 & 0.000 & 0.000 & & $\checkmark$ & \\
\hline & Computational Time & 0.000 & 0.000 & 0.000 & & $\checkmark$ & \\
\hline
\end{tabular}




\begin{tabular}{|l|l|l|l|l|l|l|l|}
\hline Shekel & Yield & 0.000 & 0.000 & 0.000 & & & $\checkmark$ \\
\hline & Design Point & 0.000 & 0.006 & 0.000 & & $\checkmark$ & \\
\hline & Computational Time & 0.000 & 0.000 & 0.000 & & $\checkmark$ & \\
\hline Styblinski & Yield & 0.000 & 0.000 & 0.000 & $\checkmark$ & & $\checkmark$ \\
\hline & Design Point & 0.000 & 0.000 & 0.000 & & $\checkmark$ & \\
\hline & Computational Time & 0.000 & 0.000 & 0.000 & & $\checkmark$ & \\
\hline
\end{tabular}

Table 5. Performance measures on all tested problems with three, four and fives process variables

\begin{tabular}{|l|c|c|c|}
\hline Performance Measure & Good & Poor \\
\hline Best So Far Response & ACO & ST & SA \\
\hline Insensitivity to Noise & ACO & ST & SA \\
\hline Design Point & SA & ACO & ST \\
\hline Computational Time & SA & ST & ACO \\
\hline
\end{tabular}

Table 6. Advantage and disadvantage of all response surface algorithms on noisy unconstrained response surface optimisation problems

\subsection{Constrained response surface optimisation}

Industrial problems of turning machining and spring force models were also use to determine the performances of the algorithms. Hati and Rao (HR) model is the mathematical functions for a multi-pass turning optimisation of the mild steel work-piece using a carbide tool. An objective function is to minimise a production cost in dollars/piece. Ermer (E) and Ermer and Kromodihardjo (EK) models minimise a production cost in dollars/piece for single pass turning. Iwata, Oba and Murotsu (IOM) model has been proposed for multi-pass turning operation of medium carbon steel using carbide tool where an objective is to minimise the production cost in yens/piece (Khan et al., 1997). A spring force (SP) model is finally applied to study the performance of the algorithms. The mathematical model is defined to maximise a spring force which reacts to spring conditions or parameters.

A. HR-model

$\operatorname{MIN} \operatorname{COST}=\mathrm{n}\left(3141.59 \mathrm{~V}^{-1} \mathrm{f}^{-1} \mathrm{~d}^{-4}+2.879 \times 10^{-8} \mathrm{~V}^{4} \mathrm{f}^{0.75} \mathrm{~d}^{-0.025}+10\right)$

Subject to the following constraints:

(1) Minimal and maximal cutting speeds $(\mathrm{m} / \mathrm{min})$ :

$50 \leq \mathrm{V} \leq 400$

(2) Minimal and maximal feed rates $(\mathrm{mm} / \mathrm{rev})$ :

$0.30 \leq \mathrm{f} \leq 0.75$

(3) Allowable range of depths of cut $(\mathrm{mm})$ :

$1.20 \leq \mathrm{d} \leq 2.75$

(4) Cutting force $(\mathrm{kg})$ :

FC $\leq 85$

; where

$$
F_{C}=\left(28.10 V^{0.07}-0.525 V^{0.5}\right) d \times f\left(1.59+0.946 \frac{(1+x)}{\sqrt{(1-x)^{2}+x}}\right)
$$

and

$$
x=\left(\frac{V}{142} \exp (2.21 f)\right)^{2}
$$

(5) Cutting power $(\mathrm{kW})$ :

Pc $\leq 2.25$ 
; where

$$
\mathrm{P}_{\mathrm{C}}=\frac{0.746 \mathrm{~F}_{\mathrm{C}} \mathrm{V}}{4500}
$$

(6) Tool life (min):

; where

$$
\mathrm{TL}=60\left(\frac{10^{10}}{\mathrm{~V}^{5} \mathrm{f}^{1.75} \mathrm{~d}^{0.75}}\right)
$$

(7) Temperature $\left({ }^{\circ} \mathrm{C}\right)$

$\mathrm{T} \leq 1000$

; where

$$
\mathrm{T}=132 \mathrm{~V}^{0.4} \mathrm{f}^{0.2} \mathrm{~d}^{0.105}
$$

(8) Limitations on the value of the depth of cut in removing ' $A$ ' in ' $n$ ' passes:

$(\mathrm{A}=5 \mathrm{~mm} . \mathrm{d}=2.5 \mathrm{~mm}$.)

$$
\frac{\mathrm{A}}{\mathrm{d}}=\mathrm{n}
$$

\section{B. E-model}

MIN COST $=1.25 \mathrm{~V}^{-1} \mathrm{f}^{-1}+1.8 \times 10^{-8} \mathrm{~V}^{3} \mathrm{f}^{0.16}+0.2$

Subject to the following constraints:
(1) Surface finish ( $\mu$ in):
$\mathrm{SF} \leq 100$
; where $\mathrm{SF}=1.36 \times 10^{8} \mathrm{~V}^{-1.52} \mathrm{f}^{1.004}$
(2) Feed rate (in/rev):
$\mathrm{F} \leq 0.01$
(3) Cutting force (hp):
$\mathrm{HP} \leq 2.0$
; where $\mathrm{HP}=3.58 \mathrm{~V}^{0.91} \mathrm{f}^{0.78}$
C. EK-model
MIN COST $=1.2566 \mathrm{~V}^{-1} \mathrm{f}^{-1}+1.77 \times 10^{-8} \mathrm{~V}^{3} \mathrm{f}^{0.16}+0.2$

Subject to the following constraints:
(1) Feed rate (in/rev):
$\mathrm{f} \leq 0.1$
(2) Horse power (hp):
$\mathrm{HP} \leq 4$
; where $\mathrm{HP}=2.39 \mathrm{~V}^{0.91} \mathrm{f}^{0.78} \mathrm{~d}^{0.75}$
$\mathrm{SF} \leq 50$

(3) Surface finish $(\mu \mathrm{in})$ :
; where $\mathrm{SF}=204.62 \times 10^{6} \mathrm{~V}^{-1.52} \mathrm{f}^{1.004} \mathrm{D}^{0.25}$

D. IOM-model

MIN COST $=\sum_{i=1}^{n} 3927 \mathrm{~V}_{\mathrm{i}}^{-1} \mathrm{f}_{\mathrm{i}}^{-1}+1.95 \times 10^{-8} \mathrm{~V}_{\mathrm{i}}^{2.88} \mathrm{f}_{\mathrm{i}}^{-1} \exp \left(5.884 \mathrm{f}_{\mathrm{i}}\right) \mathrm{d}_{\mathrm{i}}^{-1.117}+60$

Subject to the following constraints:

(1) Minimal and maximal feed rates $(\mathrm{mm} / \mathrm{rev})$ :

$0.001 \leq \mathrm{f} \leq 5.6$

(2) Minimal and maximal cutting speeds $(\mathrm{m} / \mathrm{min})$ :

$14.13 \leq \mathrm{V} \leq 1005.3$

(3) Minimal and maximal depth of cut $(\mathrm{mm})$ :

$0 \leq \mathrm{d} \leq \mathrm{A}$ ; where ' $\mathrm{A}$ ' is the depth of material to be cut.

(4) Maximal cutting force $(\mathrm{kg})$ :

$\mathrm{FC} \leq 170$

; where $\mathrm{F}_{\mathrm{C}}=290.73 \mathrm{~V}^{-0.1013} \mathrm{f}^{0.725} \mathrm{~d}$

(5) Stable cutting region related to the cutting surface:

$\mathrm{fV}^{2} \geq 2230.5$ 
(6) Maximal allowed surface roughness:

$0.356 f^{2} \leq \mathrm{H}_{\max }$

; where $\mathrm{H}_{\max }$ ranges from 0.01 to $0.06 \mathrm{~mm}$.

(7) Maximal power consumption $(\mathrm{kW})$ :

; where $\mathrm{P}_{\mathrm{C}}=\frac{\mathrm{F}_{\mathrm{C}} \mathrm{V}}{4896}$

(8) The sum of depths of cut of the ' $n$ ' passes used to remove the total depth ' $A$ ' of the material

$$
\sum_{i=1}^{n} d_{i}=A
$$

E. SP-model

$$
\operatorname{MAX} f(X)=\left(300+16 x_{5}\right)\left(\frac{140}{x_{1}}-1\right)+x_{3}\left(x_{2}+\left(x_{5}-20\right)\left(\frac{280}{x_{1}}-1\right)-x_{4}\right)\left(\frac{280}{x_{1}}-1\right)
$$

Subject to the following constraints:

(1) Minimal and maximal edge of paper which faces to shaft:

$100 \leq x_{1} \leq 180$

(2) Minimal and maximal joint of spring:

$35 \leq \mathrm{x}_{2} \leq 75$

(3) Minimal and maximal strength of spring:

$5 \leq \mathrm{x}_{3} \leq 15$

(4) Minimal and maximal compression distance of spring:

$20 \leq \mathrm{x}_{4} \leq 50$

(5) Minimal and maximal paper thickness:

$0 \leq \mathrm{x}_{5} \leq 50$

This section presents the performance study of the algorithms on industrial problems. Cost minimisation from a turning machine is determined at different conditions i.e. a cutting speed, a feed rate, a depth and a cutting force illustrated from the previous section. In addition, a spring test is also studied in different conditions of independent factors such as a joint, strength and a compression distance to maximise the spring force. The ACO and an integrated algorithm of the SA and ACO, HYBRID, are proposed to eliminate a disadvantage of the computational time. The results are summarised in Tables 7-9 below.

\begin{tabular}{|c|c|c|c|c|c|c|c|c|}
\hline \multirow{2}{*}{$\begin{array}{c}\text { Performance } \\
\text { Measure }\end{array}$} & \multicolumn{9}{|c|}{ TR } & \multicolumn{2}{c|}{ E } & \multicolumn{2}{c|}{ EK } & \multicolumn{2}{c|}{ IOM } \\
\cline { 2 - 9 } & $\begin{array}{c}\text { Design } \\
\text { point }\end{array}$ & Yield & $\begin{array}{c}\text { Design } \\
\text { point }\end{array}$ & Yield & $\begin{array}{c}\text { Design } \\
\text { point }\end{array}$ & Yield & $\begin{array}{c}\text { Design } \\
\text { point }\end{array}$ & Yield \\
\hline Mean & 14532 & 79.28 & 7200 & 6.29 & 7200 & 1.55 & 14954 & 122.6 \\
\hline S & 13 & 0.153 & 0 & 0.034 & 0 & 0.000 & 26.8 & 0.050 \\
\hline Max & 14555 & 79.60 & 7200 & 6.39 & 7200 & 1.55 & 15005 & 122.6 \\
\hline Min & 14508 & 79.14 & 7200 & 6.26 & 7200 & 1.55 & 14923 & 122.5 \\
\hline SN2 & - & 37.98 & - & 15.97 & - & 3.82 & - & 41.8 \\
\hline
\end{tabular}

Table 7. Detailed results of turning machining problems through the ACO

From the ANOVA table for the HR-model (Table 10), it can be seen that both proposed heuristics were statistically significant in this case with a $95 \%$ confidence interval since having the P-value less than or equal to 0.05 . The ACO significantly contributed the best solution for all industrial problems. Almost responses from the ACO were better than the HYBRID as described in Table 11 and the box-plots (Fig. 16). However, the HYBRID which was developed from the SA and ACO enabled to search the optimal response of constrained 
problems faster. That is the strong point of the simulated annealing algorithm. However, it has to trade off searching ability for the optimal response with the computational time. The selection of the suitable method based on the types of problems should be carefully considered as shown in Table 12.

\begin{tabular}{|c|c|c|c|c|c|c|c|c|}
\hline \multirow{2}{*}{$\begin{array}{c}\text { Performance } \\
\text { Measure }\end{array}$} & \multicolumn{9}{|c|}{ HR } & \multicolumn{2}{c|}{ E } & \multicolumn{2}{c|}{ EK } & \multicolumn{2}{c|}{ IOM } \\
\cline { 2 - 9 } & $\begin{array}{c}\text { Design } \\
\text { point }\end{array}$ & Yield & $\begin{array}{c}\text { Design } \\
\text { point }\end{array}$ & Yield & $\begin{array}{c}\text { Design } \\
\text { point }\end{array}$ & Yield & $\begin{array}{c}\text { Design } \\
\text { point }\end{array}$ & Yield \\
\hline Mean & 6000 & 79.44 & 6000 & 6.31 & 6000 & 1.56 & 6000 & 124.01 \\
\hline S & 0 & 0.12 & 0 & 0.02 & 0 & 0.002 & 0 & 0.75 \\
\hline Max & 6000 & 79.61 & 6000 & 6.33 & 6000 & 1.56 & 6000 & 125.64 \\
\hline Min & 6000 & 79.22 & 6000 & 6.27 & 6000 & 1.55 & 6000 & 122.73 \\
\hline SN2 & - & 38.00 & - & 16.00 & - & 3.84 & - & 41.87 \\
\hline
\end{tabular}

Table 8. Detailed results of turning machining problems through the HYBRID

\begin{tabular}{|c|c|c|c|c|}
\hline \multirow{2}{*}{$\begin{array}{c}\text { Performance } \\
\text { Measures }\end{array}$} & \multicolumn{2}{|c|}{ ACO } & \multicolumn{2}{c|}{ HYBRID } \\
\cline { 2 - 5 } & $\begin{array}{c}\text { Design } \\
\text { point }\end{array}$ & Yield & $\begin{array}{c}\text { Design } \\
\text { point }\end{array}$ & Yield \\
\hline Mean & 1968640 & 3166.56 & 7393 & 2604.85 \\
\hline S & 927 & 125.03 & 470 & 162.50 \\
\hline Max & 1970073 & 3368.71 & 8165 & 2926.80 \\
\hline Min & 1967196 & 2869.09 & 6750 & 2372.61 \\
\hline SN1 & - & 69.992 & - & 68.281 \\
\hline
\end{tabular}

Table 9. Detailed results of a spring force problem through the ACO and the HYBRID

\begin{tabular}{|l|l|c|c|c|c|c|}
\hline \multicolumn{1}{|c|}{ Source } & DF & SS & MS & F & $\begin{array}{c}\text { P- } \\
\text { Value }\end{array}$ & \\
\hline Heuristics & 1 & 0.2016 & 0.2016 & 10.76 & 0.003 & \\
\hline Error & 28 & 0.5247 & 0.0187 & & & \\
\hline Total & 29 & 0.7263 & & & & \\
\hline
\end{tabular}

Table 10. ANOVA table and the main effect plot of the process yields on the HR-model

\begin{tabular}{|c|l|c|c|c|}
\hline Model & \multicolumn{1}{|c|}{ Response } & P-Value & ACO & HYBRID \\
\hline HR & Mean of Yield & 0.003 & $\checkmark$ & \\
\hline & Stdev of Yield & 0.403 & & \\
\hline & SN2 & 0.027 & $\checkmark$ & \\
\hline & Design Point & 0.000 & & $\checkmark$ \\
\hline & Computational Time & 0.000 & $\checkmark$ & \\
\hline E & Mean of Yield & 0.121 & & \\
\hline & Stdev of Yield & 0.379 & & \\
\hline & SN2 & 0.245 & & \\
\hline
\end{tabular}




\begin{tabular}{|c|l|c|c|c|}
\hline & Design Point & 0.000 & & $\checkmark$ \\
\hline & Computational Time & 0.000 & $\checkmark$ & \\
\hline EK & Mean of Yield & 0.000 & $\checkmark$ & \\
\hline & Stdev of Yield & 0.009 & $\checkmark$ & \\
\hline & SN2 & 0.001 & $\checkmark$ & \\
\hline & Design Point & 0.000 & & $\checkmark$ \\
\hline & Computational Time & 0.000 & $\checkmark$ & \\
\hline IOM & Mean of Yield & 0.000 & $\checkmark$ & \\
\hline & Stdev of Yield & 0.001 & $\checkmark$ & \\
\hline & SN2 & 0.006 & $\checkmark$ & \\
\hline & Design Point & 0.000 & & $\checkmark$ \\
\hline & Computational Time & 0.000 & $\checkmark$ & \\
\hline & Mean of Yield & 0.000 & $\checkmark$ & \\
\hline & Stdev of Yield & 0.908 & & \\
\hline & SN1 & 0.044 & & $\checkmark$ \\
\hline & Design Point & 0.000 & & $\checkmark$ \\
\hline & Computational Time & 0.000 & & $\checkmark$ \\
\hline
\end{tabular}

Table 11. Performance measures on all constrained problems

Turning Machine - Hati and Rao

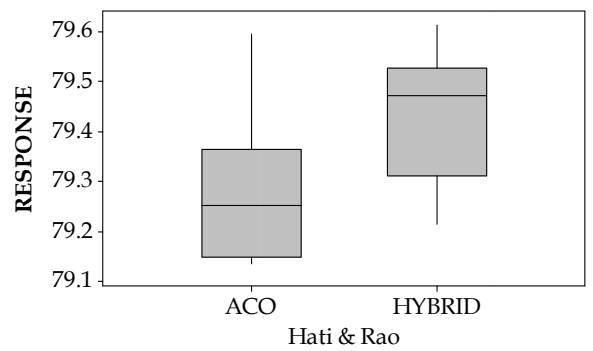

Spring Force Problem

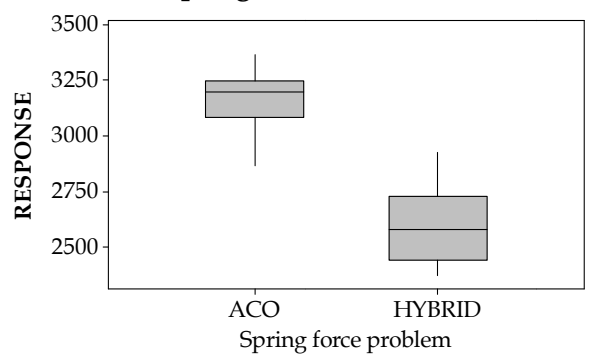

Fig. 16. Box plot of the minimal operating cost for the turning machine and the maximal force for the spring problems

\begin{tabular}{|l|c|c|}
\hline Performance Measure & Good & Poor \\
\hline Best So Far Response & ACO & HYBRID \\
\hline Design Point & HYBRID & ACO \\
\hline Computational Time & HYBRID & ACO \\
\hline
\end{tabular}

Table 12. Advantage and disadvantage of the algorithms on constrained response surface optimisation problems

\section{Conclusions and recommendations}

For two process variable cases without noise, three performance achievements on all proposed algorithms were not different for all shapes of response surfaces. The computational time for all algorithms was merely the same in each surface. When lower 
levels of noise have been indicated in the surfaces, the computational time was increased as expected but not statistically significant. The ST seems to be more efficient, in terms of speed of convergence, but there was no difference on all performance achievements when compared. When the higher levels of noise applied, SA gave the better performance achievements. Based on overall surfaces and process variables, the preferable operating conditions were obtained by the ACO, especially on response surfaces with more than four process variables. However, the weakest point of the ACO is the higher levels of computational time for searching the best response. The effects of the number of process variables on the computational time were also increased significantly for all proposed algorithms except the SA. The SA was then more efficient than others, in terms of numbers of runs for finding the maximum, but some of these runs did lead to relatively lower yields.

Hence, we tried to combine the ACO with the SA to eliminate that weakness whilst searching for the optimum. A hybridisation of the SA and the ACO is then developed for the refinement of constrained response surfaces of turning process and spring force problems. Results in the last experiments indicated that the hybridisation method worked faster but the better solution can be still achieved by the ACO. There is only a success in reducing the computational time for constrained response surface problems that is the strong point of the SA. However, it has to trade off searching ability for the optimal response with the computational time. Further applications on other processes could be determined to confirm the performance.

In summary, the ACO seems to work more properly on unconstrained response surface problems at the lower levels of noise whereas the SA is preferable when higher noise levels applied. On constrained response surface optimisation problems, the hybridisation of the $\mathrm{ACO}$ and the SA seems to be better than the ACO in terms of speed of convergence. However, the ACO can search for the better yield. As stated earlier, the response surfaces on this research were restricted to some proposed number of process variables and systems. Consequently, comparisons and conclusions between the algorithms may not be valid for other families of functions. Other stochastic approaches such as harmony search, bees or variable neighbourhood search algorithms could be extended to the steepest ascent algorithm based on conventional factorial designs to increase its performance.

It should be remembered that these algorithms are being considered for automatic process control (APC) in which case there will not usually be any operator interaction. Many repetitions of the same design are quite feasible in this context. In particular, not applying EVOP corresponds to repetitions at the current operating conditions. The algorithms can be used as the basis for a feedback control, for which stability is guaranteed. In a practical application the yield would be measured on the process and actuators would set the process variables to the new design positions.

\section{Acknowledgments}

This work was supported by the Thailand Research Fund (TRF), the National Research Council of Thailand (NRCT), the Commission on Higher Education of Thailand and the Industrial Statistics and Operational Research Unit (ISO-RU), the Department of Industrial Engineering, Faculty of Engineering, Thammasat University, THAILAND. 


\section{References}

Blum, C. \& Roli, A. (2003). Metaheuristics in Combinatorial Optimisation: Overview and Conceptual Comparison. ACM Computing Surveys, Vol. 35, No. 3, pp. 268-308

Bohachevsky, I.O.; Johnson M.E. \& Stein, M.L. (1986) Generalised Simulated Annealing for Function Optimisation. Technometrics, Vol. 28, No. 3, pp. 209-217

Box, G.E.P. \& Draper, N.R. (1987). Empirical Model-Building and Response Surfaces. John Wiley \& Sons, Inc., New York

Dasgupta, D. (1998). Artificial Immune Systems and their Applications. Springer-Verlag

Dorigo, M. \& Blum, C. (2005). Ant Colony Optimisation Theory: A survey. Theoretical Computer Science, Vol. 344, No.2-3, pp. 243-278

Dorigo, M.; Maniezzo V. \& Colorni, A. (1996). Ant System: Optimisation by a Colony of Cooperating Agents. IEEE Transactions on Systems, Man, and Cybernetics Part B, Vol. 26, numéro 1, pp. 29-41

Dorigo, M. \& Stutzle, T. (2004). Ant Colony Optimisation. Bradford Book, Massachusetts

Eusuff, M.; Lansey, K. \& Pasha, F. (2006). Shuffled Frog-Leaping Algorithm: A Memetic Metaheuristic for Discrete Optimisation. Engineering Optimisation, Vol. 38, No. 2, pp. 129-154

Glover, F. (1986). Tabu Search - Part i". ORSA Journal on Computing, Vol. 1, No. 3, pp. 190-206

Goldberg, D.E. (1989). Genetic Algorithms in Search, Optimisation and Machine Learning. Addison-Wesley, Massachusetts

Hart, E.A. \& Timmis, J. (2008). Application Areas of AIS: The Past, the Present and the Future. Applied Soft Computing, Vol. 8, No. 1, pp. 191-201

Haykin, S. (1999). Neural Networks: A Comprehensive Foundation. Prentice Hall, New Jercy

Kennedy, J. \& Eberhart, R.C. (2001). Swarm Intelligence. Morgan Kaufmann Publishers, San Francisco, CA

Khan, Z.; Prasad, B., \& Singh, T. (1997). Machining Condition Optimisation by Genetic Algorithms and Simulated Annealing, Computers Ops Res., Vol. 24, pp. 647-657

Kirkpatrick, S.; Gelatt, C.D. Jr., \& Vecchi, M.P. (1983) Optimisation by Simulated Annealing. Science, Vol. 220, pp. 671-680

Merz, P. \& Freisleben, B. (1999). A Comparison of Memetic Algorithms, Tabu Search, and Ant Colonies for the Quadratic Assignment Problem", Proceedings of Evolutionary Computation, pp. 2063-2070, IEEE Press

Myers, R.H. \& Montgomery, D.C. (1995). Response Surface Methodology: Process and Product Optimisation Using Designed Experiments, John Wiley, New York

Taguchi, G. \& Wu, Y. (1980). Introduction to Off-Line Quality Control. Central Japan Quality Control Association, Nagoya 
Simulated Annealing.

Theory with Applications

estes by hui chibants

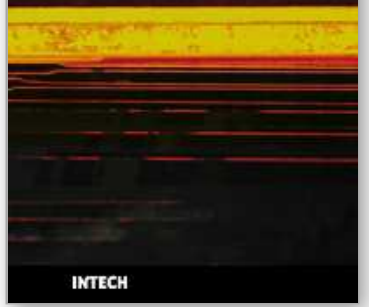

\section{Simulated Annealing, Theory with Applications}

Edited by Rui Chibante

ISBN 978-953-307-134-3

Hard cover, 292 pages

Publisher Sciyo

Published online 18, August, 2010

Published in print edition August, 2010

The book contains 15 chapters presenting recent contributions of top researchers working with Simulated Annealing (SA). Although it represents a small sample of the research activity on SA, the book will certainly serve as a valuable tool for researchers interested in getting involved in this multidisciplinary field. In fact, one of the salient features is that the book is highly multidisciplinary in terms of application areas since it assembles experts from the fields of Biology, Telecommunications, Geology, Electronics and Medicine.

\section{How to reference}

In order to correctly reference this scholarly work, feel free to copy and paste the following:

Pongchanun Luangpaiboon (2010). Simulated Annealing and its Hybridisation on Noisy and Constrained Response Surface Optimisations, Simulated Annealing, Theory with Applications, Rui Chibante (Ed.), ISBN: 978-953-307-134-3, InTech, Available from: http://www.intechopen.com/books/simulated-annealing--theorywith-applications/simulated-annealing-and-its-hybridisation-on-noisy-and-constrained-response-surfaceoptimisations-

\section{INTECH}

open science | open minds

\section{InTech Europe}

University Campus STeP Ri

Slavka Krautzeka 83/A

51000 Rijeka, Croatia

Phone: +385 (51) 770447

Fax: +385 (51) 686166

www.intechopen.com

\section{InTech China}

Unit 405, Office Block, Hotel Equatorial Shanghai

No.65, Yan An Road (West), Shanghai, 200040, China

中国上海市延安西路65号上海国际贵都大饭店办公楼 405 单元

Phone: +86-21-62489820

Fax: +86-21-62489821 
(C) 2010 The Author(s). Licensee IntechOpen. This chapter is distributed under the terms of the Creative Commons Attribution-NonCommercialShareAlike-3.0 License, which permits use, distribution and reproduction for non-commercial purposes, provided the original is properly cited and derivative works building on this content are distributed under the same license. 